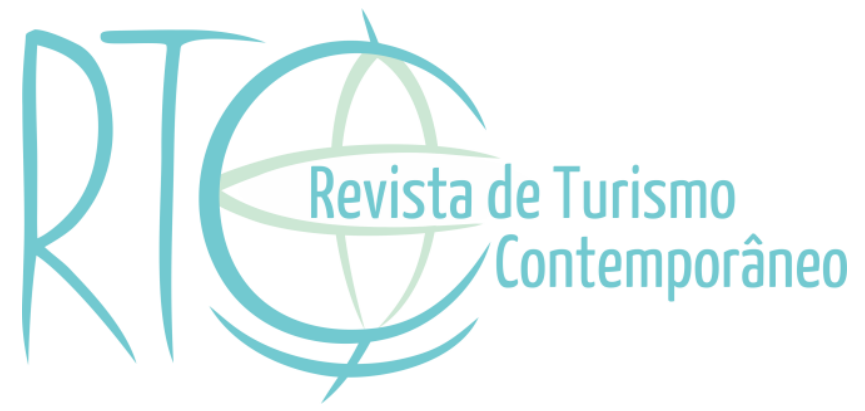

\title{
Visitação no parque estadual da Cantareira (PEC): Reflexões sobre o uso recreativo de uma Unidade de Conservação (UC)
}

\section{Visitation in the Cantareira State Park (PEC): Reflections on the recreational use of a Convervation Unity (UC)}

\author{
Alessandra Freire dos Reis \\ Doutoranda da Escola Superior de Agricultura Luiz de Queiroz da Universidade de São Paulo \\ - ESALQ/USP, Piracicaba/SP, \\ Brasil E-mail: freire.le@gmail.com
}

Odaléia Telles Marcondes Machado Queiroz

Professora da Escola Superior de Agricultura Luiz de Queiroz da Universidade de São Paulo ESALQ/USP, Piracicaba/SP, Brasil

E-mail: odaleiaq@terra.com.br

Artigo recebido em: 19-08-2015

Artigo aprovado em: 08-03-2017 


\begin{abstract}
RESUMO
Vivemos num mundo de expressivo desenvolvimento em diferentes aspectos. Em contraponto, assistimos a devastação de recursos naturais e mudanças significativas nas características da terra. Entre as atividades de destaque no mundo atual está o turismo. Este apresenta diversos nichos e especificidades, entre elas o ecoturismo que procura colocar o visitante em contato com locais que preservem aspectos ambientais e culturais. O Brasil é um país que se destaca nesse contexto, pois apresenta riquíssima diversidade de biomas e paisagens. Observa-se que o potencial tem sido pouco aproveitado quando comparado a outros países similares. Para proteger locais de significativa relevância ambiental e cultural são criadas unidades de conservação, em que se enquadram os parques. Estes tem dentro dos objetivos a visitação com atividades de lazer, recreação, educação ambiental e ecoturismo. $\mathrm{O}$ Brasil possui inúmeros parques em seu território, porém muitos não estão preparados para receber o visitante. Este artigo faz uma reflexão sobre o uso desses espaços tendo como objeto o Parque Estadual da Cantareira, localizado na Região Metropolitana de São Paulo. É destacada a possibilidade de concessão dessas áreas e o potencial pouco utilizado que os parques podem ter como instrumento de conscientização e educação ambiental, histórica e cultural.
\end{abstract}

Palavras-chave: Unidade de conservação. Lazer. Recreação. Ecoturismo.

\title{
ABSTRACT
}

We live at a time of significant development in different aspects. In contrast, we have seen the devastation of natural resources and significant changes in land features. Between prominent activities in the world today is tourism. This presents various niches and specificities, including ecotourism that seeks to put the visitor in touch with places that preserve environmental and cultural aspects. Brazil is a country that stands out in this context, it presents rich diversity of biomes and landscapes. It is observed that the potential has been little advantage when compared to other similar countries. To protect sites of significant environmental and cultural relevance are created conservation units to which they belong parks. These have within the objectives visitation with leisure activities, recreation, environmental education and ecotourism. Brazil has numerous parks in its territory, but many are not prepared to receive visitors. This paper reflects on the use of these spaces having as object the Cantareira State Park located in the Metropolitan Region of São Paulo. It highlighted the possibility of granting these areas and the potential underutilized that parks can have as awareness tool and environmental education, history and culture. It highlighted the possibility of granting these areas and the potential underutilized that parks can have as awareness tool and environmental education, history and culture.

Keywords: Protected Area. Recreation. Leisure. Ecotourism. 


\section{INTRODUÇÃO}

Vivemos num período de expressivo desenvolvimento, proporcionado pela capacidade de produção, novas tecnologias, deslocamento, entre outras. Observa-se que os indivíduos alcançaram nos últimos tempos melhoria no bem-estar e na qualidade de vida, ainda que em muitos lugares haja pessoas vivendo em situação de extrema miséria.

O avanço assistido nos últimos tempos pela humanidade proporcionou melhores condições de vida para muitas pessoas, porém acarretou concomitantemente severos danos ao meio natural. $\mathrm{O}$ crescimento populacional concentrado na cidade é responsável por muitos problemas ambientais. A gestão urbana inadequada e a falta de planejamento no crescimento das cidades tem acarretado degradação dos recursos como poluição de corpos d'água e do ar, assoreamento, impermeabilização do solo, geração e acúmulo de lixo e carência de espaços de lazer e a recreação. Estes estão entre as necessidades humanas ocupando muitas vezes parcela considerável do tempo livre das pessoas. Espaços públicos destinados a estas atividades são fundamentais no planejamento urbano para contribuir na qualidade de vida da população.

Áreas naturais protegidas, denominadas no Brasil como Unidades de Conservação (UC), são espaços criados, dentre outras finalidades, para a conservação. Porém, algumas categorias são destinadas também para atividades de lazer e recreação tendo importante função de uso público, especialmente quando localizadas em áreas urbanizadas (Brasil, 2004).

O contato com a natureza tem sido cada vez mais procurado como válvula de escape para o stress vivenciado nos grandes centros urbanos, causado pela poluição sonora e estética, pelo trânsito cada dia mais caótico, entre outras. Observa-se que inúmeras atividades têm sido desenvolvidas em áreas naturais para satisfazer as necessidades de contato e vivência no espaço natural. Essas atividades vão de simples caminhadas contemplativas a esportes radicais, que exigem maiores habilidades, equipamentos e planejamento para sua execução, como escalada e arborismo, por exemplo.

A biodiversidade do Brasil está entre as mais diversas do planeta. Seu território é composto por biomas singulares como a Mata Atlântica, a Amazônia, o Cerrado e a Caatinga. Cada um com suas particularidades apresentam expressiva variedade e formas de vida, muitas ainda nem conhecidas e descritas pela ciência. A riqueza dos biomas brasileiros e a heterogeneidade cultural do país são atrativos únicos para oferta de produtos turísticos diversificados e de qualidade (Brasil, 2010, p. 11). 
Gerenciar e proteger esses recursos são um enorme desafio, pois a conservação dos mesmos tem como o contraponto o crescimento de cidades, o avanço da agricultura, e das diversas formas de desenvolvimento e expansão econômica.

Este artigo pretende trazer algumas reflexões sobre o tema tendo como objeto o Parque Estadual da Cantareira (PEC), Unidade de Conservação, localizada na Região Metropolitana de São Paulo (RMSP), maior aglomerado urbano do país. Trata-se da região mais complexa no que se diz respeito a planejamento urbano e sustentabilidade, dado que concentra uma população que ultrapassa 20 milhões de pessoas de acordo com dados do IBGE com carência de mobilidade, qualidade de vida e espaços públicos para lazer e recreação (Brasil, 2014).

\section{REFERENCIAL TEÓRICO}

Áreas destinadas a atividades de lazer e recreação são fundamentais para qualidade de vida da população urbana. Dentre os equipamentos destinados para tal finalidade existem clubes recreativos, associações de esporte, praças e parques.

A denominação de parque é utilizada para dois tipos de áreas distintas, que comumente são confundidas: os parques urbanos e os parques como categoria de unidade de conservação. O primeiro engloba grandes áreas localizadas em áreas urbanas, com a função principal de serem áreas para lazer e recreação da população local. Apresentam exemplares da flora e fauna e equipamentos como quadras poliesportivas, playgrand, museus, ciclovias, espaço para exposição e eventos, entre outros. Dados da prefeitura de São Paulo revelam que o município possui mais de 100 parques urbanos municipais como o Ibirapuera, Villa Lobos, Água Branca, Juventude, Anhanguera, por exemplo.

O segundo trata-se de Unidade de Conservação, ou áreas naturais protegidas instituídas pelo poder público, que tem como principal objetivo a conservação de importantes atributos ecológicos e serviços ambientais, embora também seja destinada a pesquisa e ao lazer e a recreação (Brasil, 2004). Como exemplo no RMSP tem-se o Parque Estadual da Cantareira, o Parque Estadual Alberto Löfgren e o Parque Estadual do Jaraguá.

Internacionalmente o órgão destinado a tratar do tema de áreas protegidas é o WCPA (Word Comission and Protected Areas), vinculado a IUCN (International Union for Conservation of Nature). Define seis tipos de áreas protegidas por categorias de governança e tipos de manejo. Dentre essas categorias estão os Parques Nacionais. Quanto à governança a 
IUCN - WCPA (2016), define quatro tipos: governança pela governança, governança compartilhada, governança privada e governança por povos indígenas e comunidades tradicionais.

O Brasil possui um sistema próprio denominado Sistema Nacional de Unidades de Conservação (SNUC), "com 12 categorias dividas em dois grupos, com características específicas: unidades de proteção integral e unidades de uso sustentável” (Brasil, 2004, p.13). Os parques estão dentro da categoria de proteção integral, que são aquelas que têm como objetivo preservar a natureza, sendo admitido apenas o uso indireto dos seus recursos naturais.

Os parques têm como objetivo básico a preservação de ecossistemas naturais de grande relevância ecológica e beleza cênica, possibilitando a realização de pesquisas científicas e o desenvolvimento de atividades de educação e interpretação ambiental, de recreação em contato com a natureza e de turismo ecológico (BrasiL, 2004, p. 14).

São as unidades de conservação mais conhecidas, pois dentre seus principais objetivos está a visitação. Podem ser nacionais, estaduais ou municipais. O Brasil possui inúmeros parques, porém muitos estão fechados ao uso público, impedindo o direito dos cidadãos de usufruir desses espaços. Falta de infraestrutura, funcionários e segurança são algumas das razões para o não uso desses espaços. Segundo Richard e Chináglia (2004), as experiências em áreas naturais tem um reconhecido potencial para fins recreativos ao fornecer oportunidades para revitalizar sensações e proporcionar emoções prazerosas. O debate sobre a necessidade de conservação do meio ambiente atinge a atividade turística inserindo uma nova maneira de vivenciar e usufruir o meio natural (Brasil, 2010). Tem como facilitador a premissa do "conhecer para preservar".

No congresso mundial de parques, realizado em Sidney em 2014 defendeu-se que “os parques deverão ser lugares de interação de múltiplos valores: ecológico, biológico, cultural, social, econômico e estético" (Andersen \& Hoeflich, 2015, p. 08). Dentre os segmentos do turismo, que apresenta expressivo aumento nos últimos anos está o ecoturismo. Este é responsável pelo fluxo de turistas em busca de lugares paradisíacos em todo o mundo. "Pressupõe atividades que promovam a reflexão e a integração homem e o ambiente. Deve ser planejado visando o envolvimento do turista nas questões relacionadas à conservação dos recursos" (Brasil, 2010, p. 18). Por outro lado tem implicações sociais devido às transformações que gera na distribuição do acesso a recursos naturais. Como demonstra Kent (2003), ao mesmo tempo em que explora que habitats naturais depende da preservação destes.

A Região Metropolitana de São Paulo possui a maior concentração populacional do país, ultrapassando 20 milhões de habitantes (Brasil, 2014). Deste modo, é proporcional a 
demanda por atividades de recreação e lazer. A expansão da malha urbana extinguiu boa parte dos recursos naturais locais, oferecendo assim poucas oportunidades de contato com a natureza.

Um dos desafios fundamentais para gestão de parques em áreas urbanas é alcançar equilíbrio entre proteção da biodiversidade e proporcionar oportunidades para os visitantes de desfrutar e apreciar a natureza. Para tanto é necessário incorporar os princípios de desenvolvimento sustentável ao planejamento, desenvolvimento e gestão, a fim de compatibilizar conservação e uso público das áreas (Corkery \& Corkery, 2015, p. 29).

De acordo com Andrade et al (2009), poucas unidades de conservação dividem a missão de conciliar conservação com oportunidade de lazer na RMSP. Entre eles podem-se citar os Parques Estaduais Alberto Löfgren (conhecido como Horto Florestal), do Juquery, do Jaraguá e do Guarapiranga, porém sem a mesma magnitude e complexidade do PEC, uma vez que estes parques são menores e não apresentam a sua biodiversidade. A Figura 1 apresenta as UC da região.

Figura 1. Unidades de conservação da Região do PEC.

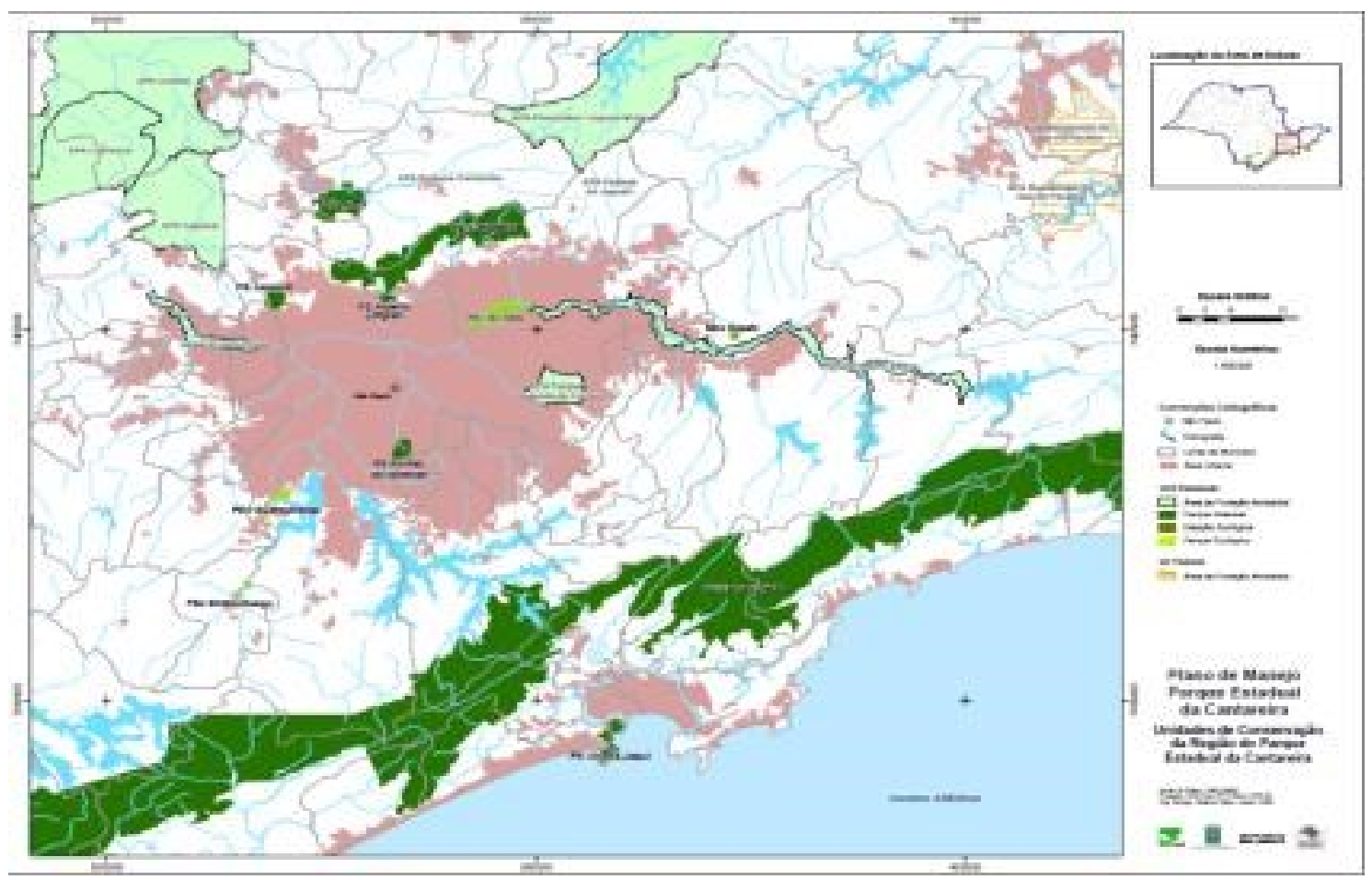

Fonte: São Paulo, 2009. 


\section{METODOLOGIA}

Este é um artigo de revisão teórica sobre o uso publico em unidades de conservação. Utilizou-se como referências bibliográficas livros, teses, artigos e a legislação pertinente ao tema da pesquisa e a área de estudo. O Parque Estadual da Cantareira, Unidade de Conservação de proteção integral, localizada na Região Metropolitana de São Paulo, teve como objetivo através da pesquisa fazer uma reflexão sobre o uso e o potencial turístico e de lazer nesta UC.

\section{ANÁLISE E DISCUSSÃO DOS RESULTADOS}

“A Região Metropolitana de São Paulo (RMSP) é o $5^{\circ}$ maior aglomerado urbano do mundo, abrangendo a capital do Estado e outros 38 municípios vizinhos numa superfície de 805.300 hectares” (São Paulo, 2009, p. 01). "O Maciço da Cantareira alonga-se na direção nordeste-sudoeste por cerca de $30 \mathrm{~km}$, ocupando uma área de aproximadamente $320 \mathrm{~km}^{2}$ onde é possível identificar grande heterogeneidade na cobertura vegetal" (São Paulo, 2009, p. 04).

Dentre os serviços ambientais prestados pela Serra da Cantareira destaca-se a produção de água, sendo dos principais elementos que garante a vida de qualquer ser vivo na terra. A segurança hídrica é vital para manutenção de qualquer atividade ambiental, social ou econômica. O estágio de evolução que alcançamos hoje, tem colocado esse recurso em riscos sem precedentes. O desperdício, a poluição e a má gestão, tem nos levado a uma situação alarmante, como pode ser claramente observado atualmente no Estado de São Paulo.

Devido a esta importante função desde o século XIX, esforços foram empreendidos no sentido de proteger a área, culminando na criação do parque. "O Sistema Cantareira de Águas é responsável por $46 \%$ do abastecimento de água da RMSP se caracterizando como maior e principal manancial" (São Paulo, 2009, p. 05). Atualmente, devido a diversos fatores como falta de planejamento urbano, perda da cobertura florestal, entre outros, este sistema está severamente comprometido.

Os recursos hídricos da Serra da Cantareira abastecem a população paulista desde 1881. Nesta época suas águas chegavam à rede distribuidora por força gravitacional. Posteriormente, com a crescente urbanização de São Paulo, a demanda foi aumentando, sendo criado então o Sistema Cantareira inaugurado em 1973 (São Paulo, 2009, p. 10).

A área tem sido tema de destaque e polêmica pela alarmante crise de água ocorrida em 2014 e que se mantém preocupante nos dias atuais e também devido à construção do 
último trecho do Rodoanel Mario Covas - trecho norte. Este foi concebido para desafogar o trânsito na capital, porém sua construção causará impactos significativos no bioma da região.

“As terras que compõem o Parque Estadual da Cantareira foram adquiridas e tombadas pelo Estado no final do XIX como Reserva Florestal para a preservação das fontes de água que abastecem até hoje a cidade de São Paulo" (São Paulo, 2009, p. 10). Tornou-se Parque Estadual com a edição da Lei Estadual No 6.884, de 29 de agosto de 1962, regularizada pelo Decreto Estadual no 41.626, de 30 de janeiro de 1963. Em 1968 finalmente é publicado o decreto que oficializa a criação do Parque (Decreto Estadual n ${ }^{0} 10.228$, de 24 de setembro de 1968), nomeando-o na época como Parque Turístico (São Paulo, 2009, p. 11). Abrange os municípios de São Paulo, Guarulhos, Mairiporã e Caieiras conforme apresenta a Figura 2.

Figura 2. Municípios abrangidos pelo Parque Estadual da Cantareira.

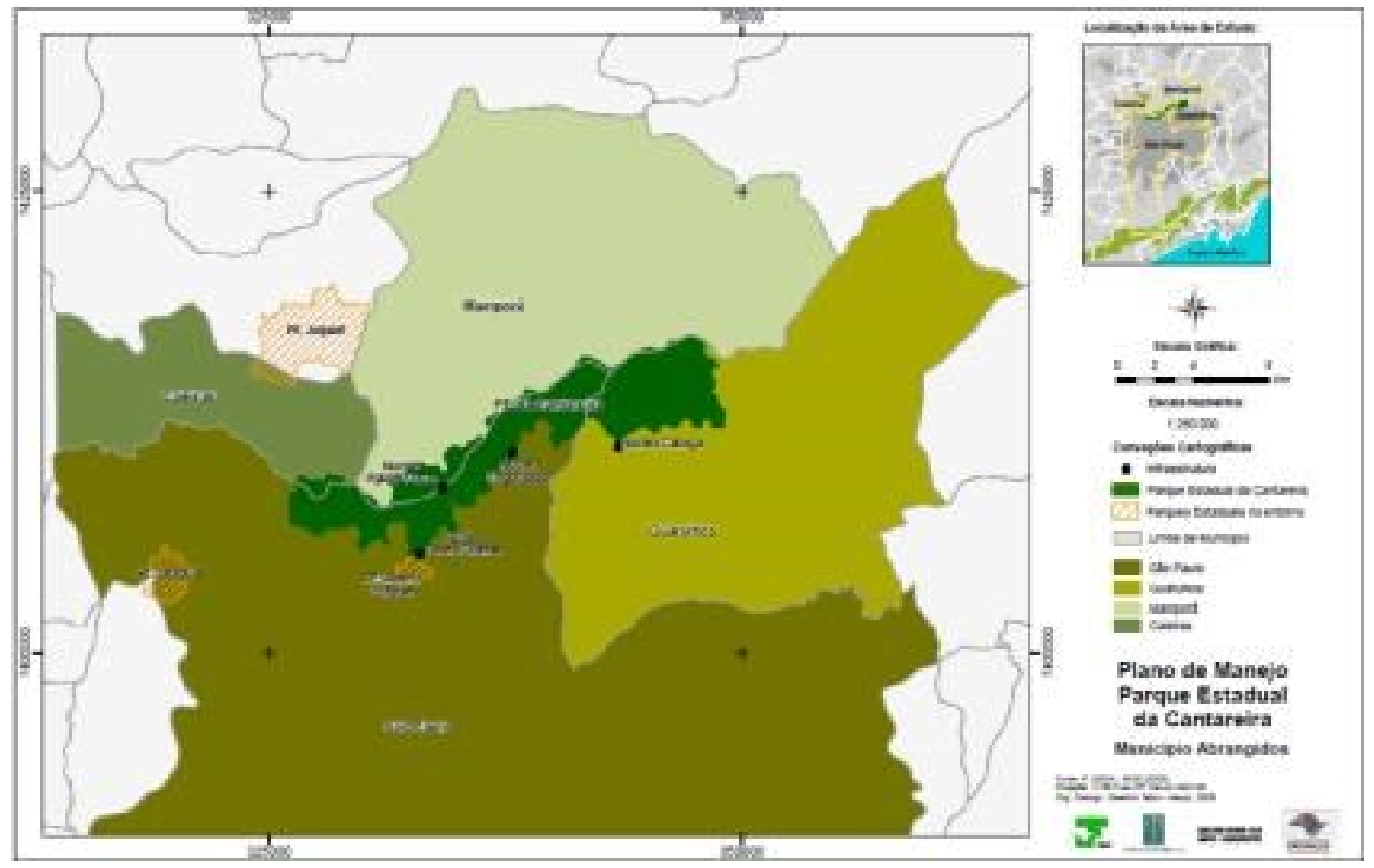

Fonte: São Paulo, 2009.

A utilização dos parques para atividades de lazer, recreação, educação ambiental e ecoturismo é um direito das pessoas garantido pela legislação. Porém, o atendimento ao visitante demanda uma série de adequações desses locais para que a experiência seja a mais enriquecedora e segura possível.

Um parque para receber visitantes necessita de instalações adequadas e funcionários. Estas necessidades variam de unidade para unidade dependendo da localização, tamanho e 
tipos de atrativos que oferece. É extremamente heterogêneo os tipos de parque que encontramos no território nacional em termos de bioma e dimensão. Há parques como o Parque Nacional da Amazônia com tamanho de 1.084.895,62 (ha) e outros como o Parque Estadual do Jaraguá com área de 491,98 (ha), por exemplo ( Brasil, 2017; São Paulo, 2017) . Além disso, há ainda diferenças no acesso, no entorno e na distância dos polos emissores de visitantes.

Os parques são áreas do poder público, sendo assim sua gestão é atribuição destes. No caso dos parques nacionais do Instituto Chico Mendes de Conservação da Biodiversidade (ICMBio), nos estaduais por órgãos vinculados as secretarias de meio ambiente, no caso de São Paulo a Fundação Florestal (FF), e no caso dos municipais as secretarias municipais de meio ambiente.

A criação de um parque demanda a instalação de infraestrutura para sua gestão, proteção e uso público. A visitação, muitas vezes, ocorre numa pequena parcela da unidade, requer maior parte de investimentos, pois o visitante necessita de uma série de serviços como lanchonetes, sanitários, centros visitantes e, em alguns casos, hospedagem. Como dito anteriormente, cada unidade é um caso específico. O PEC, por exemplo, possui quatro núcleos de visitação com centros de visitantes, porém nenhum oferece serviços de alimentação e hospedagem.

Uma boa governança é fundamental para o sucesso, em que recursos limitados só poderão ser eficazmente utilizados com base numa avaliação cuidadosa de desempenho do passado e previsão de necessidades futuras e que muitas vezes é um processo empreendido por várias partes e não somente pelo governo (Shields et al, 2016, p. 37).

Existe o debate para que a gestão turística das unidades de conservação seja feita pela iniciativa privada, uma vez que os governos argumentam não ter capacidade de investimento nessas áreas. Recentemente uma nota sugeriu que o Ministério do Turismo assumisse a visitação dos parques nacionais. Em relação ao tema Mantovani (2015), membro da SOS Mata Atlântica, fez a seguinte observação:

Para que haja avanços efetivos no setor, é importante a cooperação entre os órgãos gestores de Meio Ambiente, do Turismo e outras pastas, bem como a participação da sociedade e iniciativa privada, com foco nas áreas de interesse turístico, que são áreas estratégicas e prioritárias para conservação.

Recentemente foi aprovada, no Estado de São Paulo, a Lei N ${ }^{\circ} 16.260$, de 29 de junho de 2016 que, "autoriza a Fazenda do Estado a conceder a exploração de serviços ou o uso, 
total ou parcial, de áreas em próprios estaduais". Estão inclusas na referida lei 25 áreas protegidas, sendo 13 parques estaduais, dentre eles o Parque Estadual da Cantareira.

Tem-se observado um debate latente sobre o tema, que divide a opinião de especialistas e atores envolvidos na questão. Dentre as principais críticas está à falta de clareza da forma que se darão tais concessões e a ausência de diálogos com as comunidades tradicionais, que vivem no entorno ou em áreas sobrepostas a algumas unidades de conservação.

Há distintas formas de o Estado ceder os bens públicos a terceiros, sendo possível a autorização, a permissão ou a concessão. Nenhumas dessas modalidades significam a privatização dos bens como tem sido constantemente divulgado. É urgente qualificar o debate para que informações errôneas deixem de se propagar.

Como demostra Rodrigues e Godoy (2013),

A compreensão sobre as diferentes modalidades de prestação de serviços e de suas respectivas características importa para planejar a gestão da visitação considerando aspectos como envergadura econômica, número de usuários, entre outras.

$\mathrm{O}$ receio e críticas de ambientalistas e comunidades tradicionais referem-se à incapacidade do Estado de fiscalizar os concessionários, uma vez que as UCs tem padecido de falta de investimentos em infraestrutura e pessoal. $\mathrm{O}$ debate sobre a concessão das unidades de conservação é importante, pois o uso público demanda bastante atenção e tempo da gestão das UCs com atendimento ao público, a implantação e manutenção de equipamentos.

Entretanto é necessário que haja uma ampla consulta dos interessados e pesquisadores da área. $\mathrm{O}$ que se observa é que conselhos consultivos e corpo técnico não são consultados para avaliar e opinar pelas decisões políticas acerca do destino dessas áreas.

Estudo realizado por Shields et al (2016), demostra a importância da participação dos stakeholders na gestão de áreas protegidas, assim como relatórios públicos disponíveis sobre as mesmas. Segundo os autores, o interesse pelas partes interessadas ilustra a tendência da governança das áreas protegidas se tornarem um sistema multi-nível, emponderando e engajando uma variedade de participantes.

É necessário ressaltar que no Brasil não há ainda uma cultura forte de envolvimento e participação. Existem diversos modelos de concessão que podem ser aplicados aos parques a partir de parcerias entre a iniciativa privada e as agências públicas. Segundo Collins (2014) “nos Estados Unidos a partir de 1965 companhias privadas operam em parques nacionais, provendo aos visitantes serviços de apoio ao turismo, tais como alimentação, hospedagem, transporte, etc". 
No Brasil, desde 1999 o Parque Nacional de Foz do Iguaçu tem a visitação administrada por uma concessionária. A concessão prevê a gestão do centro de visitantes, Porto Canoas, Naipi e Tarobá, além de implantação do sistema de transporte no seu interior. Este Parque está entre os mais visitados do Brasil e recebeu 1.560.792 visitantes no ano de 2016 segundo dados do ICMBio (Brasil, 2017). Sabe-se que esta realidade não se aplica a maioria das unidades, pois não possuem atrativos tão singulares quanto às cataratas. Alguns parques do Estado de São Paulo como o de Campos de Jordão e Caverna do Diabo, por exemplo, possuem permissão de uso para exploração de esportes de aventura como arborismo, tirolesa e aluguel de bicicletas e também loja de souvenirs, café e restaurante.

O Parque Estadual da Cantareira não tem serviços concedidos até o presente momento, mas está na lista da lei aprovada. Observa-se que a Lei $n^{\circ} 16.260$ é extremamente genérica aos aspectos que se referem às atividades de visitação como se pode contatar em seu Artigo $2^{\circ}$ :

\footnotetext{
São objetivos desta lei:

I - permitir, criar e favorecer condições à exploração do potencial ecoturístico das áreas;

XIV - criar e favorecer condições e promover a educação ambiental, a recreação e o lazer em contato com a natureza;
}

Tais objetivos são premissas de uma unidade de conservação de categoria, Parque definidos no SNUC e no regulamento de parques estaduais. Vale ressaltar, que a Lei deveria ter sido regulamentada num prazo de 180 dias, fato que ainda não ocorreu. Espera-se que a regulamentação traga maior clareza e transparência nos termos das concessões das UCs. Recentemente foi realizada uma representação que pede abertura de Ação Direta de Inconstitucionalidade (ADI) contra a lei de concessão assinado pelo Instituto Socioambiental, Conselho Indigenista Missionário (CIMI), Comissão Guarani Yvyrupa, Equipe de Articulação e Assessoria às Comunidades Negras do Vale do Ribeira (EAACONE) e Defensoria Pública de São Paulo (Souza, 2017).

Observa nas UCs paulistas a falta de diálogo, sucateamento da infraestrutura, cargos comissionados com alta rotatividade e alguns casos sem qualificação técnica, ausência de plano de carreira para os servidores e a extinção dos guardas parques.

Em levantamento realizado por Souza et al (2016), o tempo médio de permanência de um gestor nas UC paulistas é de aproximadamente de 18 meses. Para os autores a inexistência de estratégias para garantir a estabilidade do gestor na sua função causa enormes danos para a gestão de uma UC. Observa-se também expressiva rotatividade do cargo de diretor executivo da FF com nove diferentes diretores no período de uma década como pode 
ser consultado no site da instituição. Esta realidade demonstra a descontinuidade na política ambiental do Estado.

É fato que a visitação nos parques no Brasil é ainda muito tímida diante do potencial e da diversidade de atrativos. Países com características similares como a Costa Rica possuem um número mais expressivo de visitação. Um estudo realizado pela Instituto Semeia em 2013 aponta que a maior parte das unidades pesquisadas, que permitem uso público recebeu até 10.000 visitantes no ano de 2012 (51\% da amostra total). Esse número é muito pequeno diante de tanto potencial. O resultado da pesquisa pode ser observado na Figura 3.

Figura 3. Distribuição de visitantes nas UCs pesquisadas.

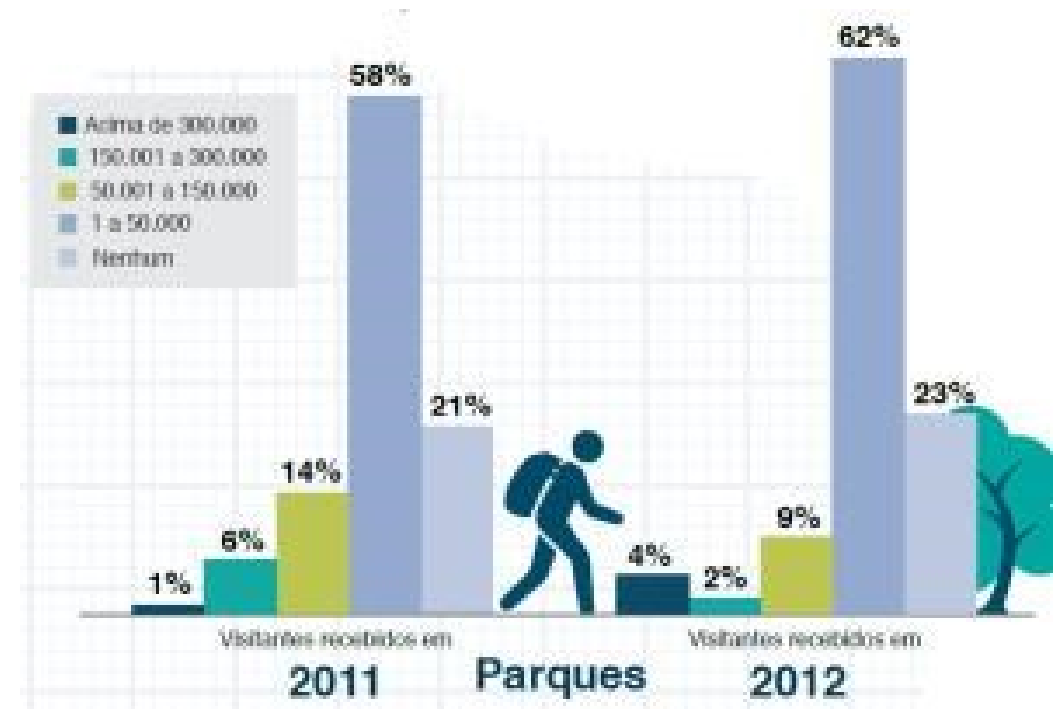

Fonte: SEMEA, 2013.

De acordo com dados do Ministério do Meio ambiente (MMA) este cenário está evoluindo como pode ser constatado no gráfico da visitação nas unidades de conservação federais, porém ainda há muitos desafios para potencializar o uso das áreas protegidas em todo território nacional. 
Figura 4. Visitação nas unidades de conservação federais entre os anos de 2007 á 2016.

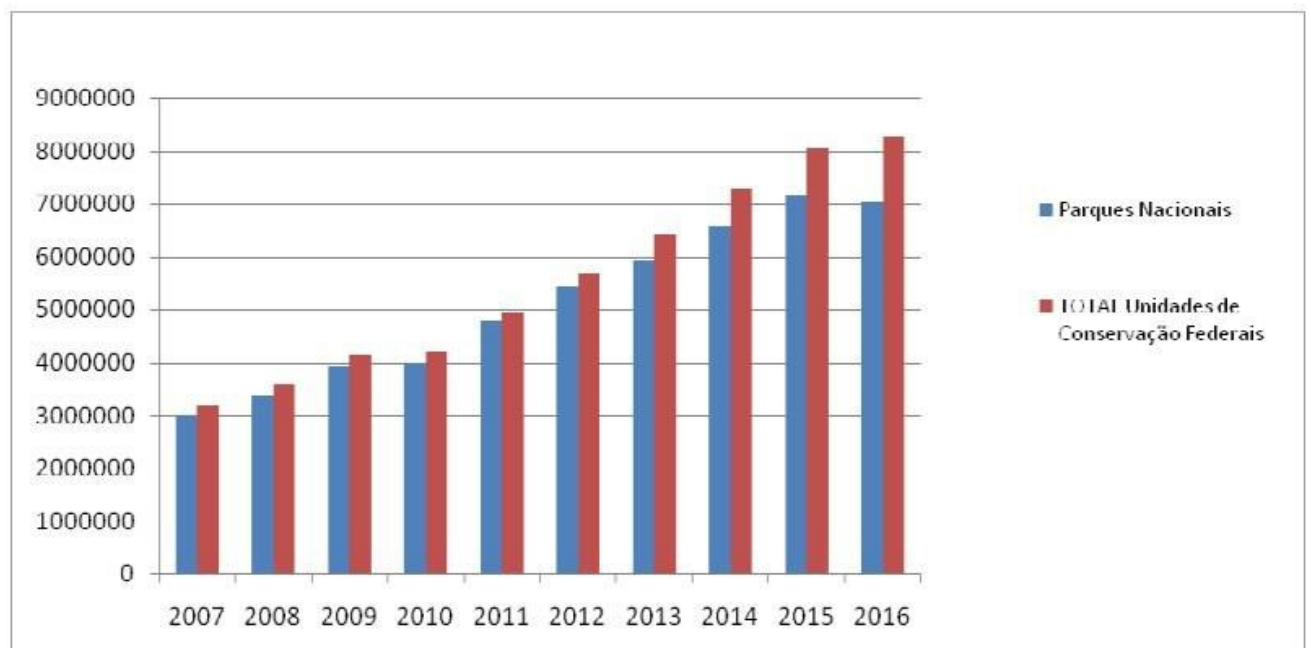

Fonte: BRASIL (2017).

\subsection{O Parque Estadual da Cantareira}

O Parque Estadual da Cantareira é considerado uma das maiores áreas naturais protegidas dentro de limites urbanos no mundo (São Paulo, 2009, p. 393) e faz parte da Reserva da Biosfera do Cinturão Verde da Cidade de São Paulo, conforme declaração da Organização das Nações Unidas para a Educação, Ciências e Cultura - UNESCO. De acordo com Andrade et al (2009) sua área é de 7.916,52 ha e perímetro de $91 \mathrm{~km}$ entre os municípios de São Paulo, Caieiras, Mairiporã e Guarulhos. Possui quatro Núcleos de visitação estruturados: Pedra Grande, Engordador, Águas Claras e Cabuçu.

"Estima-se que abriga um total de 388 espécies de vertebrados, dos quais 97 são mamíferos, 233 são aves, 28 são anfíbios, 20 são répteis e 10 são peixes (São Paulo, 2009, p. 20)". É considerado pela BirdLife International com área importante para conservação de aves no Brasil (IBAs). Nos dias da semana os núcleos são fechados para visitação e atendem por agendamento especialmente grupos escolares para estudo do meio. As trilhas são autoguiadas, mas há monitores para prestar informação. O ingresso custa $\mathrm{R} \$ 13,00$ (crianças menores de 12 anos, adultos com mais de 60 anos, pessoas com deficiência e moradores do entorno cadastrados não pagam). Estudantes pagam meia-entrada.

O Núcleo Pedra Grande localizado no município de São Paulo abriga a sede do Parque e recebe o maior número de visitantes com 65.103 no ano de 2016 (São Paulo, 2017). Tem como atrativos, trilhas interpretativas e um afloramento rochoso de granito, que dá nome ao Núcleo. A Figura 2 a apresenta a vista da Pedra Grande. Para ter acesso a mesma há um caminho de asfalto que deve ser percorrido por 9,6 km (ida e volta) a partir da entrada do 
Parque. Esta imagem demostra o contraste entre o urbano e o natural onde é possível avistar diversos pontos da RMSP.

Figura 2. Vista da Pedra Grande.

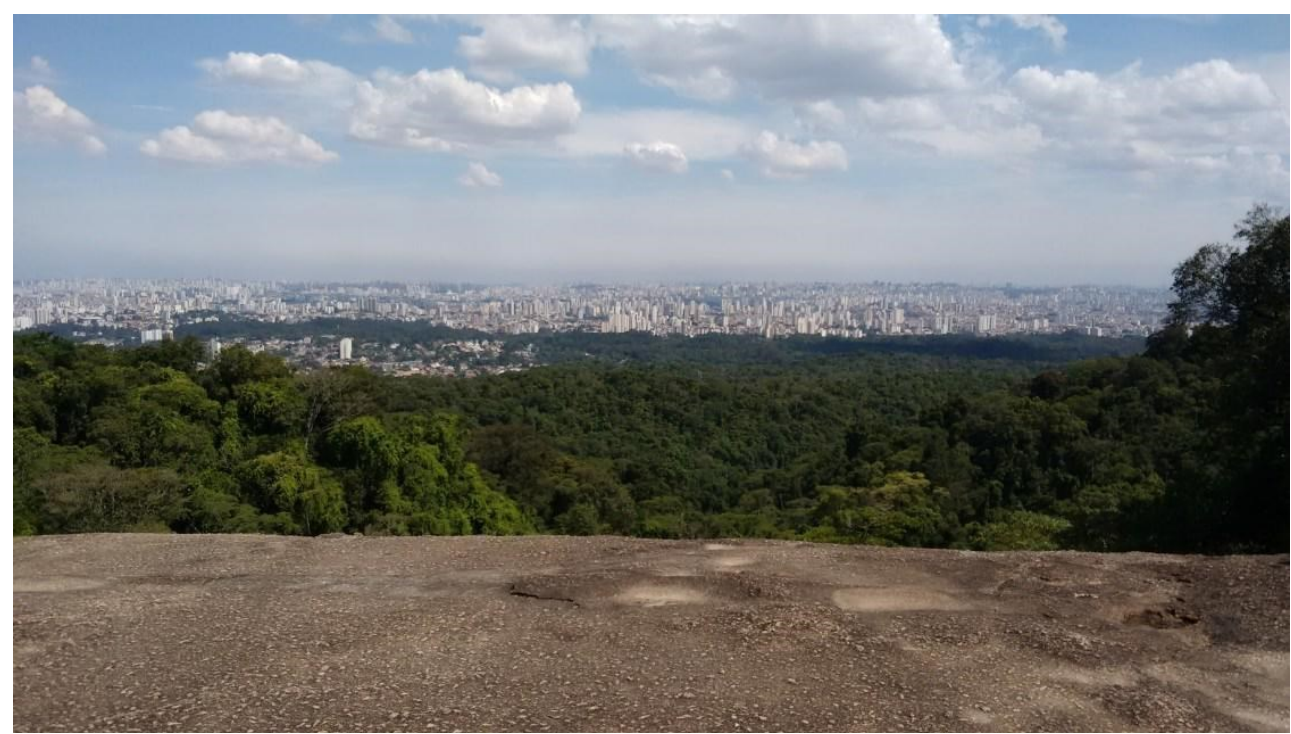

Fonte: A autora (2016).

O Núcleo Engordador também está localizado no município de São Paulo oferecendo trilhas, cachoeira e atividades de educação ambiental. Este Núcleo concentra os principais acervos da história de captação da água no município e tem como atrativo dessa época a Represa do Engordador e a Casa de Bombas. A Figura 3 mostra o maquinário utilizado no Sistema Cantareira no século passado.

Figura 3. Maquinário da Casa das Bombas Núcleo Engordador.

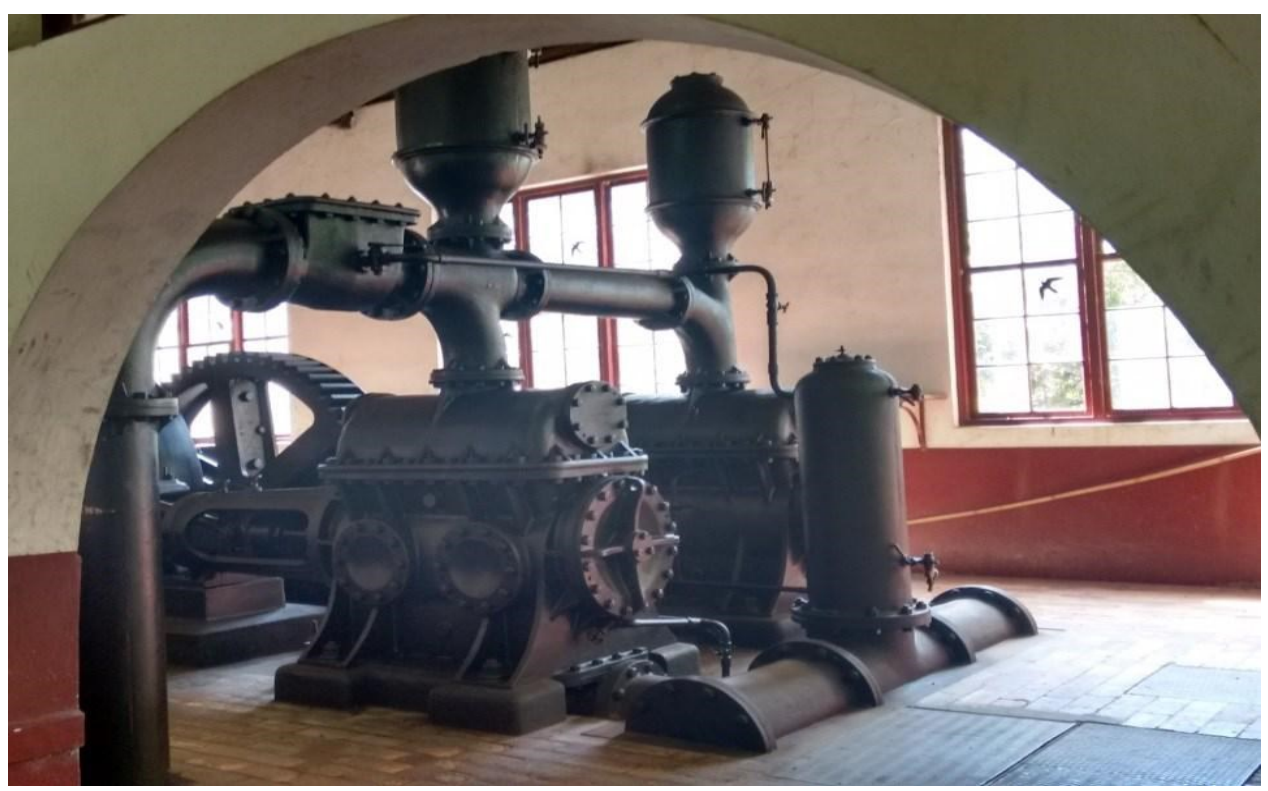

Fonte: A autora (2016). 
O Núcleo Águas Claras localiza-se no município de Mairiporã e é o menos visitado, pois o acesso é restrito a veículos particulares devido à estrada que não permite a passagem de ônibus. Possui trilhas interpretativas e o Lago de carpas, local destinado a contemplação e área de piquenique. $\mathrm{O}$ entorno é caracterizado por condomínios de alto padrão.

O núcleo Cabuçu localiza-se no município de Guarulhos e foi aberto à visitação somente em 2008 (São Paulo, 2009, p. 12). Este também possui uma represa associada ao abastecimento de água, que está em funcionamento e possui também trilhas interpretativas e cachoeira. Possui o entorno de comunidades carentes e atende maior número de visitantes cadastrados para isenção do ingresso tendo a missão de suprir as necessidades de espaços de lazer e recreação em meio natural (São Paulo, 2016).

De acordo com Alvez e Raimundo (2009), a observação da fauna também é um dos atrativos do Parque com significativa variedade de avifauna e destaque para o macaco bugio (Allouata clamitans), que chega a ter até 1,20 m de comprimento e faz um som característico e chamativo. A observação de aves é um dos segmentos do ecoturismo que mais cresce no mundo movimentando significativo volume de recursos em equipamentos.

O público que visita o Parque é em sua maioria da Região Metropolitana de São Paulo. Observa-se que a visitação é baixa diante do potencial e da localização da unidade de conservação, que está inserida no maior centro urbano do país. O Parque não oferece serviços ao visitante com alimentos e bebidas e souvenir, por exemplo. O oferecimento de complementos à visitação pode melhorar a experiência do visitante e contribuir na geração de receita da UC.

A principal atividade realizada no Parque é a caminhada nas diversas trilhas interpretativas, que se configuram num atrativo em si. As trilhas são o melhor meio de conhecer uma UC, pois trazem placas interpretativas de aspectos da unidade de conservação e desvendam no seu decorrer características e peculiaridades do local. As trilhas do PEC são de nível fácil a médio e apresentam bom estado de conservação.

Vale ressaltar que devido à unidade de conservação estar inserida ao redor do meio urbano, que há inúmeros tipos de uso irregulares, de trilhas não autorizadas e outros usos como depósito de lixo e entulhos, captação irregular de água, uso de entorpecentes, entre outros que geram impactos negativos na $\mathrm{UC}$.

Como mencionado, o PEC além de ter atrativos naturais de relevante beleza cênica, possui um riquíssimo patrimônio histórico relacionado ao abastecimento de água na região. Segundo Vilar (2007), o Sistema Cantareira atual foi substituído a partir de 1973 sendo que o complexo implantado no século XIX foi desativado e toda sua estrutura ficou como legado do 
patrimônio histórico do município e está protegido pelo Parque. Esse potencial poderia ser mais bem utilizado para o uso público sendo fonte de informação e conscientização ambiental, histórica e cultural.

\section{CONCLUSÕES}

O turismo e o lazer estão entre as importantes atividades realizadas no mundo contemporâneo e o segmento do ecoturismo é dos que mais cresce. A necessidade de conservação do meio ambiente se configura numa das principais pautas e desafios das nações, sento objeto de diversos acordos e convenções. O processo de desenvolvimento nos últimos tempos já nos levou a situações irreversíveis de perdas de biomas em todo mundo.

O PEC além de ter atrativos naturais de relevante beleza cênica, possui um riquíssimo patrimônio histórico relacionado ao abastecimento de água na região, o Sistema Cantareira. Esse potencial poderia ser mais bem utilizado para o uso público sendo fonte de informação e conscientização ambiental, histórica e cultural. A escassez de espaços públicos de lazer em meio natural na RMSP evidencia ainda mais a importância desta unidade de conservação.

Conciliar uso público e conservação é dos principais desafios da gestão das UCS. Há aqueles que acreditam que as unidades devam ser mantidas fechadas e manter o foco na preservação dos recursos. Porém, há uma crescente parcela de pessoas que acreditam que devam ser divulgadas e "exploradas" por visitantes, sendo fonte de renda e de educação.

O debate sobre a questão é extremamente pertinente e essa equação só pode ser resolvida diante de amplo debate claro e transparente. O que se vê atualmente no Brasil é que as regras são impostas sem que os devidos interessados sejam consultados. Esse fato tem gerado preocupação para as pessoas que se relacionam de alguma forma com a questão.

O PEC está entre as unidades de conservação selecionadas para concessão de exploração de serviços no Estado de São Paulo, porém poucas informações e nenhum debate pautado por informações técnicas e troca de experiência foi realizado. A Lei aprovada está em fase de regulamentação, mas não há informações disponíveis a respeito. As UCs selecionadas apresentam diferenças significativas entre si no que se refere à localização, realidade do entorno, presença de comunidades tradicionais e tipos de atrativos.

É preciso estar atento para esta e outras áreas não sejam simplesmente entregues a iniciativa privada por meio de contratos escusos, que não contribuam de fato com os objetivos da unidade de conservação com a valorização do patrimônio, o acesso público e irrestrito, o 
fortalecimento da participação dos atores envolvidos, assim como daqueles já atuam com a cogestão desses espaços sem serem oficialmente reconhecidos.

\section{REFERÊNCIAS}

Alvez, S. J. S., \& Raimundo, S. (2009). Percepção ambiental e as práticas do lazer em contato com a natureza no Parque Estadual da Cantareira - Núcleo Pedra Grande, São Paulo (SP). OLAM - Ciência \& Tecnologia , 9(1), 335.

Andersen \& Hoeflich. (2015). The world parks congress 2014: Inspiring solutions for parks, people and planet. Anais da IUCN WCPA. PARKS. The International Journal of Protected Areas and Conservation, 21(1). Gland, Switzerland: IUCN. Recuperado em 09 de dezembro, 2016, https://www.iucn.org/sites/dev/files/parks_21.1_low_resolution_10.2305iucn.ch_.2014.parks21-1.en_.pdf

Andrade, W. et al. (2009). Diagnóstico da visitação pública e propostas de ação para o Parque Estadual da Cantareira. Série Registros, (38), 128. São Paulo, Brasil. IF.

Brasil - Instituto Brasileiro de Geografia e Estatística (2004). Estimativas da população dos municipios brasileiros com data de Referência em $1^{\circ}$ de julho de 2014. Recuperado de http://www.ibge.gov.br/home/presidencia/noticias/pdf/analise_estimativas_2014.pdf.

Ministério do Meio Ambiente (2004). Sistema Nacional de Unidades de Conservação da Natureza. Brasília.

. Ministério do Meio Ambiente (2017) (ICMBio). ICMBio divulga dados de visitação em UCs. Recuperado em 10 de março, 2017, de http://www.icmbio.gov.br/portal/ultimasnoticias/20-geral/8711-cresce-numero-de-visitantes-nos-parques-nacionais.

. Ministério do Meio Ambiente. (2017). (ICMBio). Parna da Amazônia. Recuperado em 10 de março, 2017, de http://www.icmbio.gov.br/portal/parna-daamazonia?highlight $=$ WyJwYXJxdWUiLCIncGFycXVlIiwicGFycXV1Jy4iLCJuYWNpb25hb CIsIm5hY2lvbmFsJywiLCJkYSIsImFtYXpcdTAwZjRuaWEiLCInYW1helx 1MDBmNG5pY SIsInBhcnF1ZSBuYWNpb25hbCIsInBhenF1ZSBuYWNpb25hbCBkYSIsIm5hY2lvbmFsIG RhIiwibmFjaW9uYWwgZGEgYW1hem9uaWEiLCJkYSBhbWF6XHUwMGY0bmlhIl0=

Ministério do Turismo (2010). Ecoturismo: orientações Básicas. Brasília: Ministério do Turismo, 2008. Brasil. (2ª ed.), 90. - Brasília: Ministério do Turismo.

Corkery e Corkery (2015). Western Sydney parklands: Australia's Largest urban park. Annals of the IUCN WCPA. PARKS. The International Journal of Protected Areas and Conservation, 21(1), Gland, Switzerland: IUCN. Recuperado em 09 de dezembro, 2016, de https://www.iucn.org/sites/dev/files/parks_21.1_low_resolution_10.2305iucn.ch_.2014.parks21-1.en_.pdf.

Collins, D. (2014). Modelos de concessão em parques norte-americanos. SEMEA:2014. $\begin{array}{lllll}\text { Recuperado em } & 08 \text { de julho, } & \text { 2015, }\end{array}$ 
http://www.semeia.org.br/index.php/component/k2/item/580-resumo-t\%C3\%A9cnicomodelos-concess $\% \mathrm{C} 3 \% \mathrm{~A} 30$-parque-norte-americanos-novembro-site.

IUCN. (2016). Recuperado em 09 de dezembro, 2016, de https://www.iucn.org/sites/dev/files/parks_22.1___2016.pdf.

Kent, M. (2003). Ecotourism, environmental preservation and Conflicts over natural resources. Horizontes Antropológicos, 9(20), 185-203. Porto Alegre, outubro.

Mantovani. (2015). (SOS Mata Atlântica). Esclarecimento: parques nacionais e a gestão de áreas de interesse turístico. Recuperado em agosto, 2015, de https://www.sosma.org.br/103220/parques-nacionais-e-gestao-de-areas-de-interesse-turistico.

Richard, V, L. e Chináglia, C, R. (2004). Turismo de Aventura: conceitos e paradigmas fundamentais. Revista Turismo em Análise, 15(2), 199-215. São Paulo.

Rodrigues, C.G.O. e Godoy, L.R.C. (2013). Atuação pública e privada na gestão de Unidades de Conservação: aspectos socioeconômico prestação de serviços de apoio à visitação em parques nacionais. Revista Desenvolvimento e Meio Ambiente, 28, 75-88. Editora UFPR.

São Paulo (Estado) (2016). Lei $n^{\circ} 16.260$, de 29 de junho de 2016. Autoriza a Fazenda do Estado a conceder a exploração de serviços ou o uso, total ou parcial, de áreas em próprios estaduais que especifica e dá outras providências correlatas. Diário Oficial.

(Estado). (2009). Secretaria de Meio Ambiente (Fundação Florestal). Plano de Manejo do Parque Estadual da Cantareira. Recuperado em 15 de maio, 2015, de http://fflorestal.sp.gov.br/planos-de-manejo/planos-de-manejo-planos-concluidos.

(Estado). (2017). Secretaria de Meio Ambiente (Fundação Florestal). Unidades de Conservação - Parques Estaduais. Recuperado em 10 de março, 2017, de http://fflorestal.sp.gov.br/unidades-de-conservacao/parques-estaduais/parques-estaduais/.

(Estado). (2017). Secretaria de Meio Ambiente (Fundação Florestal). Relatório de gestão 2016 (não publicado).

SEMEIA. (2013). Gestores e Unidades de Conservação: perspectivas. SEMEIA: 2013. pdf.

Shields et al. (2016). Indicators for assessing good governance of protected areas: insights from park managers in western Australia. Annals of the UCN WCPA. PARKS. The International Journal of Protected Areas and Conservation, 22(1), Gland, Switzerland:

IUCN. Recuperado em 09 de dezembro, 2016, de https://www.iucn.org/sites/dev/files/parks_22.1_-_2016.pdf.

Souza, B, S. (2017). (Instituto Sociomabiental) ISA e organizações pedem a Janot ação contra lei de concessão de parques. Recuperado em 13 de março, 2017, de https://www.socioambiental.org/pt-br/noticias-socioambientais/isa-e-organizacoes-pedem-ajanot-acao-contra-lei-de-concessao-de-parques.

Souza, F.A.Z. et al. (2015). Mudar ou não mudar, eis a gestão? A situação dos gestores de unidades de conservação no Estado de São Paulo. Anais do $8^{\circ} \mathrm{CBUC}$ - Trabalhos Técnicos 2015. Curitiba. Recuperado em 10 de julho, 2015, de

http://eventos.fundacaogrupoboticario.org.br/CBUC/TrabalhosTecnicos?ids=1495. 
Vilar, D, D. São Paulo (2007). Água aos Cântaros- os reservatórios da Cantareira: um estudo da arqueologia industrial. Tese de doutorado. Programa de pós-graduação em Arqueologia e Etnologia da Universidade de São Paulo. 